\title{
Biocompatible Polymer Nanoparticles for Intra-cellular Applications
}

\author{
Emma M. V. Johansson ${ }^{\S}$ and Mark Bradley \\ §SCS-DSM Award for best poster presentation
}

\begin{abstract}
Polymeric styrene microspheres have a great potential at the interface of chemistry and biology. The progress of the synthetic development of multifunctional microspheres and their use as delivery agents of different biomolecules into cells is discussed. Their multifunctional properties open a wide range of applications from intracellular real-time sensors, to the use of microspheres as catalysts performing exogenous chemistry within cells.
\end{abstract}

Keywords: Cellular uptake · Delivery · in vitro Catalysis · in vitro Sensing · Microspheres

\section{Introduction}

The cell membrane is the natural barrier that protects living cells from the environment surrounding them. The ability to introduce otherwise impermeable species such as DNA, proteins and larger charged molecules into cells has been important in gaining an understanding of their function in cells. There are numerous delivery techniques that have been developed over the years, ${ }^{[1]}$ but by far the greatest advances have been achieved by the use of cell penetrating peptides, ${ }^{[2]}$ cationic lipids, ${ }^{[3]}$ dendrimers ${ }^{[4]}$ and nanomaterials. ${ }^{\left[{ }^{[5}\right]}$ It is widely believed the use of nanoparticles in medicine and biotechnology will continue to increase as demand rises for the delivery of payload and reporter systems. ${ }^{[6]}$ Delivery systems will require ever more sophisticated functionalization methods able to perform a variety of tasks. Some polymeric materials in the form of nano/ microparticles have been shown to transport encapsulated materials across cell membranes, ${ }^{[7]}$ but there remains a need for

${ }^{*}$ Correspondence: Dr. E. M. V. Johansson

School of Chemistry

University of Edinburgh

The King's Buildings

West Mains Road

Edinburgh EH9 3JJ, United Kingdom

Tel.: +441316513307

E-mail: emma.johansson@ed.ac.uk such polymeric materials, which can also be readily functionalized with desired payloads. Herein we summarize the development of readily functionalized polystyrene microspheres, their uptake into cells and the use of these as a vector of delivery.

\section{Synthesis of Microspheres}

Aminomethyl-functionalized polystyrene microspheres were synthesized using two different polymerization methods depending on the desired size: emulsifier-free emulsion polymerization giving smaller microspheres $(50-200 \mathrm{~nm})$ and dispersion polymerization producing larger sizes $(0.5-2 \mu \mathrm{m})$ (Fig. 1a). ${ }^{[8]}$ These monodisperse microspheres with surface amino moieties can be readily functionalized using standard chemistry which can be analyzed by colorimetric techniques..$^{[9]}$ Recently our group introduced a new method of analysis using the zeta potential (a property related to the surface charge ${ }^{[10,11]}$ with the zeta potential of a microsphere directly related to its surface group functionality (Fig. 1b) allowing the rapid monitoring of specific chemical reactions (Fig. 2). ${ }^{[12]}$ Covalent functionalization via amide bonds is one of the most common methods available to attach dyes and payloads to polymeric particles. ${ }^{[13]}$ However, following such functionalization the number of surface groups available for attaching further cargos is greatly reduced. This problem can be overcome by the use of bifunctional linkers, although this enhances steric

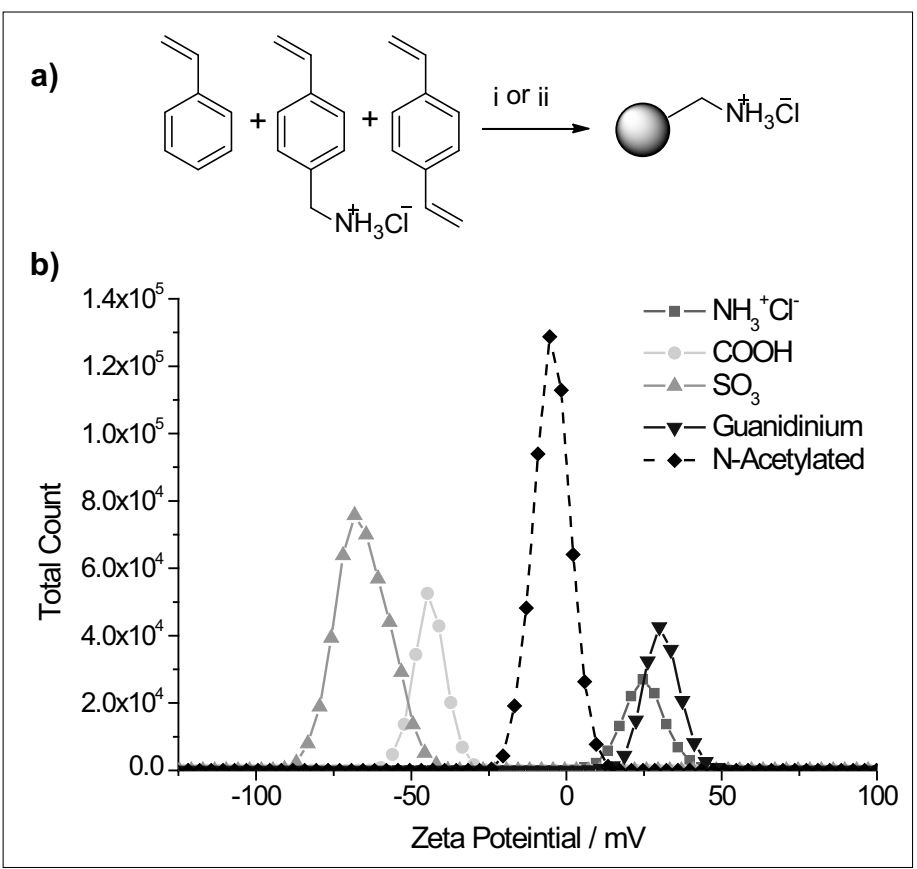

Fig. 1. a) The synthesis of polystyrene microspheres. i) Emulsifier-free emulsion polymerization: styrene, divinylbenzene (DVB), $p$-vinylbenzylamine hydrochloride (VBAH), 2,2'-azobis(2-methylpropionamidine) dihydrochloride V50 initiator, water, $\mathrm{MgSO}_{4}, 80^{\circ} \mathrm{C}, 5-15$ h; ii) Dispersion polymerization: styrene, DVB, VBAH, AIBN, ethanol/water, poly(vinylpyrrolidone), $68^{\circ} \mathrm{C}, 12$ h. b) Zeta potential of surface functionalized microspheres. ${ }^{[8,11]}$ 


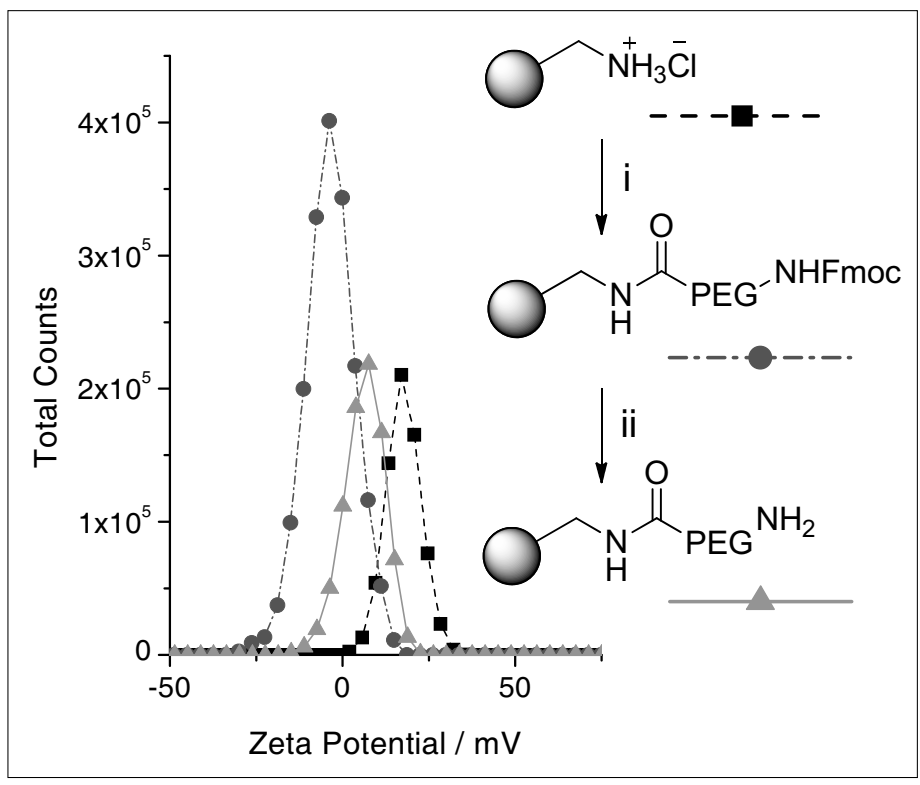

Fig 2. Reaction monitoring of a PEG spacer conjugation to a polystyrene microsphere using zeta potential: i) Fmoc-HN-PEG $-\mathrm{OH}$, Oxyma/DIC, DMF, $60^{\circ} \mathrm{C}, 60 \mathrm{~min} \mu \mathrm{w}$; ii) $20 \%$ piperidin in DMF $2 \times 20 \min ^{[12]}$

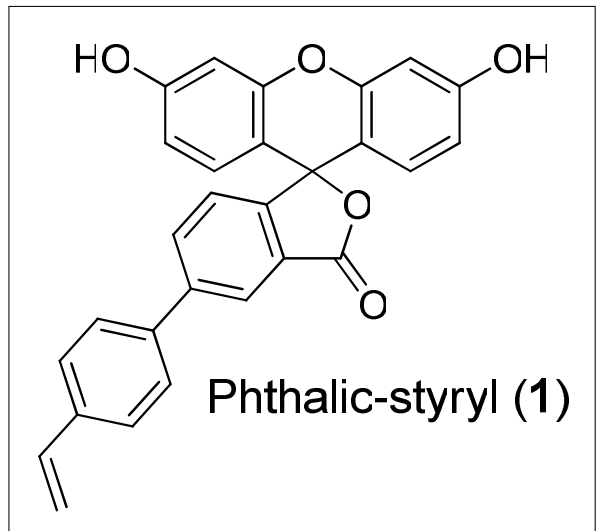

Fig 3. Structure of fluorescent dye, phthalicstyryl fluorescein (1). ${ }^{[12]}$

congestion. Therefore, alternative methods for preparing fluorescent microspheres without reducing the number of surface moieties are desired. Direct incorporation of a fluorescent dye into the polymeric backbone of the microspheres realizes this goal, and was achieved by including the styrene-functionalized dye phthalic-styryl fluorescein (1) (Fig. 3) as an additional monomer to the microsphere synthesis without changing the microsphere synthesis protocol. This allowed the generation of highly fluorescent microspheres without compromising their cargo carrying capacity. ${ }^{[12]}$ It is worth noting that this approach leads to higher emission intensity of backbone-incorporated fluorescein relative to the surface-conjugated fluorescein and a more even distribution of the fluorescent molecules throughout the particle. ${ }^{[12]}$

\section{The General Uptake of Microspheres into Cells}

Microspheres have been shown to be taken up rapidly and efficiently by a wide variety of cell types including HEK 293T, K562, B16, HeLa, A375M, ND11, mES and hES cells (Fig. 4a). ${ }^{[8,14]}$ There appeared to be no significant difference in tent or were in the process of differentiating and importantly the microspheres did not initiate differentiation in any way. ${ }^{[15]}$ Remarkably they were found to be taken up by pluripotent mouse embryonic stem cells (mES) that went on to form chimeras. ${ }^{[15]}$ The efficiency of the uptake of miuptake by stem cells that were still pluripoas a substrate. ${ }^{[31]}$ crospheres into cells is related to the size of the microspheres as well as 'exposure time' ${ }^{[8]}$ and an investigation into whether the microspheres enter via endocytosis has been conducted. ${ }^{[16]}$ It was established that microspheres do not enter via endocytosis, micropinocytosis or any other energy dependent uptake mechanism and it was shown that the uptake was slowed by a reduction in temperature. The microspheres certainly interacts with the cytoskeleton and the suggestion is that microspheres anchor to the membrane and a fast, energy independent, membrane reorganization occurs to deliver the microspheres directly into the cytosol (Fig. 4b). $[17,18]$ Microspheres appear to be a highly efficient and inert delivery system as the uptake was generally good for all cell types tested in these studies and no impact on the cell viability and no significant changes in the gene expression was observed.[16] Recently there has been a considerable speculation concerning what is involved in the initial encounter between a cell and a particle. ${ }^{[19]}$ The surface of any particle in biological media is coated with proteins, and these undoubtedly play a vital role in the particle-cell membrane interaction and the eventual uptake into the cell.[20]

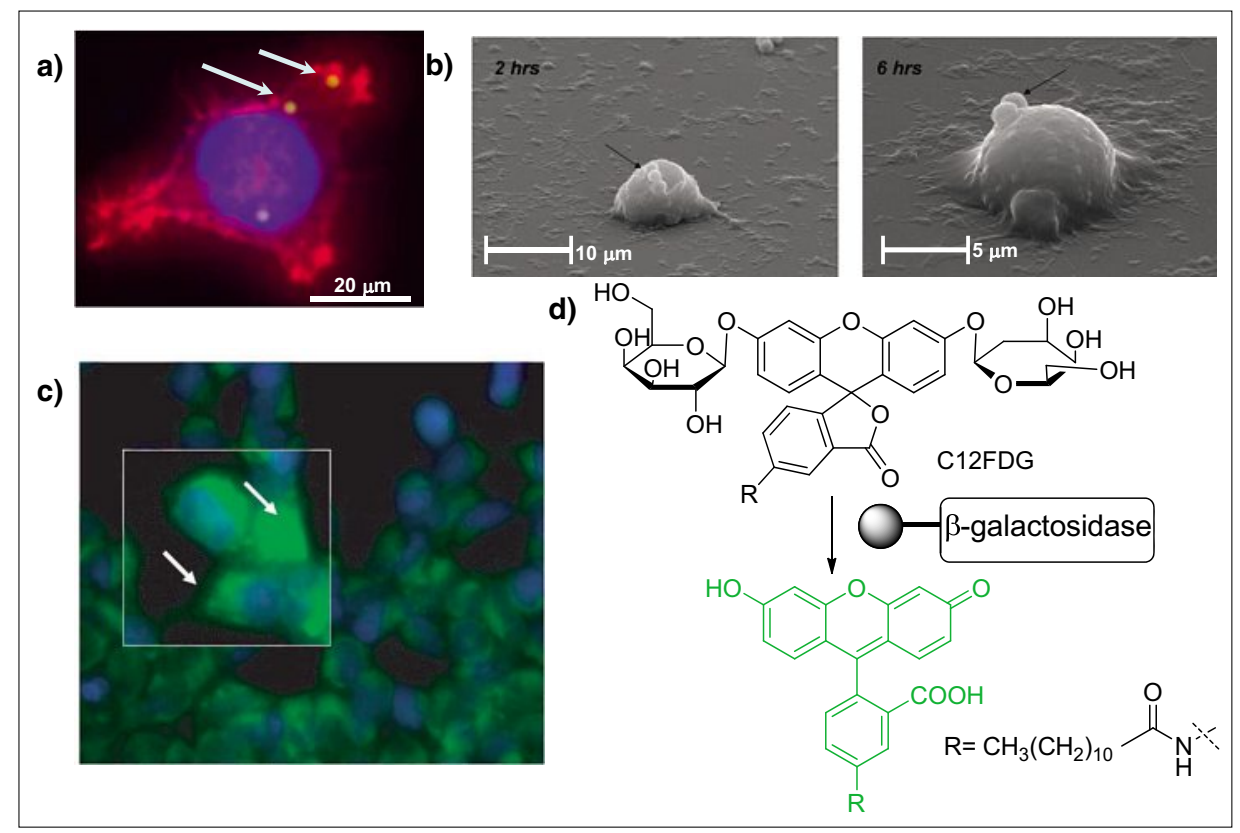

Fig. 4. a) Uptake of $2 \mu \mathrm{m}$ fluorescein labelled microspheres by B16F10 cells. The actin filaments are stained with AlexaFluor 568-phalloidin (red) and the cell nuclei are stained with Hoechst 33342 (blue) (scale bar is $20 \mu \mathrm{m}$ ). ${ }^{\left[{ }^{16]} \mathrm{b}\right.}$ ) Scanning Electron Microscopy images of B16F10 cells incubated with $2 \mu \mathrm{m}$ microspheres (black arrows) for $2 \mathrm{~h} \mathrm{(left)} \mathrm{(scale} \mathrm{bar} \mathrm{is} 10 \mu \mathrm{m}$ ), $6 \mathrm{~h}$ (right) (scale bar is $5 \mu \mathrm{m}) .{ }^{[18]} \mathrm{c}$ ) Fluorescence image of HeLa cells incubated with $500 \mathrm{~nm} \beta$-galactosidase-loaded microspheres after treatment with the fluorogenic substrate C12FDG, a derivative of di- $\beta$-Dgalactopyranoside (FDG) (white arrows indicate the green fluorescence related to cytoplasmatic release of fluorescein due to $\beta$-galactosidase activity). The nucleus was labelled with Hoechst 33342 (blue). d) The principle of fluorescent detection of $\beta$-galactosidase activity using C12FDG 


\section{The Use of Microspheres as a Delivery Vector}

The possibility to either insert or correct a faulty gene by delivery of DNA into cells is the basis of gene therapy.[21] A requirement for expression of proteins encoded on DNA is that the DNA is transported to the nucleus. Microspheres are generally restricted to the cytosol so in order to successfully use these to deliver DNA to the nucleus; a new delivery strategy with a cargo release mechanism was developed. The introduction of a disulfide linker to a carrier molecule is a well-established approach exploiting the stability of a disulfide bond in the different redox environments in the extra- and intracellular compartments. A plasmid DNA (pDNA) encoding yellow fluorescent protein was attached with a cleavable disulfide linker ensuring the release of the pDNA once the microspheres entered the cytosol. Cellular processes then transported the pDNA to the nucleus resulting in the expression of the protein. ${ }^{[22]}$ Another approach would be the delivery of synthetic siRNA into cells which has increasing applications due to the ability to switch off a genes without the necessity of being transported into the nucleus. ${ }^{[23]}$ Microspheres functionalized with a double stranded siRNA were shown to efficiently silence green fluorescent protein (eGFP) expressed in human cervical cancer (HeLa) cells. ${ }^{[24]}$ The efficiency of the silencing effect was partly due to the microspheres being directly taken up into the cytosol allowing the conjugated RNA direct access of the cells messenger RNA. ${ }^{[25]}$ There are always risks associated with potential side effect of gene therapy ${ }^{[26]}$ and the delivery of a fully functional protein into the cytosol would allow for an immediate effect by the protein as well as lowering these risks. As an example of this the protein $\beta$-galactosidase was loaded onto microspheres and was delivered to $\mathrm{HeLa}$ cells without any observable damage to the proteins function. The activity of the protein inside the cell was confirmed using a specific cell-permeable substrate which releases the fluorescent dye fluorescein upon hydrolysis by $\beta$-galactosidase (Fig. $4 \mathrm{c}, \mathrm{d}) .{ }^{[8,25]}$

The Use of Microspheres as Sensors

As the microspheres do not degrade, the possibilities of their use as reliable long-term sensors inside cells were also explored. The $\mathrm{pH}$ of the cytosol affects a wide range of processes and the function of proteins in the cell, hence it is controlled within a narrow range by ion transfer across the cellular membrane. ${ }^{[27]}$ Fluorescein is a well-known fluorescent $\mathrm{pH}$ indicator, ${ }^{[28]}$ however it is able to readily cross the cell membrane and rapidly leak from the cell, preventing its reliable use as an intracellular $\mathrm{pH}$ probe. By contrast, fluorescein immobilized onto microspheres has been shown to be an accurate $\mathrm{pH}$ sensor in the cellular range of $\mathrm{pH} 6$ to 8 with long-term stability and with no observable leakage from cells. ${ }^{[29]}$ The concentration of other ions such as calcium is equally important and well-known fluorescent $\mathrm{Ca}^{2+}$ probes like Indo- ${ }^{[30]}$ are also not easily delivered into cells. A derivative of Indo-1, covalently attached to microspheres, was successfully delivered into cells and calcium levels were evaluated at the single cell level, in real time. ${ }^{[31]}$ Cells containing the Indo-1 microsphere sensor had activity after 18 hours while the conventional sensor had completely diffused out of the cells in the same period, suggesting the microspheres may have a role as long-term sensors of cellular calcium levels. [31]

\section{The Use of Microspheres as a Carrier of Inorganic Catalysts}

The chemistry within a cell is typically carried out by a wide range of proteins. ${ }^{[32]}$ Although the use of these proteins and their mimics has been widely explored, little attention has been paid to the use of small molecule catalysts to perform chemical transformation within cells. Microspheres modified to 'contain' a heterogeneous $\operatorname{Pd}(0)$ catalyst cross the cellular membrane and remain in the cytosol for a prolonged period of time without causing any harm to the cell. These $\operatorname{Pd}(0)$-loaded microspheres retain catalytic activity within cells and a Suzuki-Miyaura cross-coupling reaction was performed allowing the synthesis of a fluorescent mitochondrial dye demonstrating the first use of a palladium catalyst

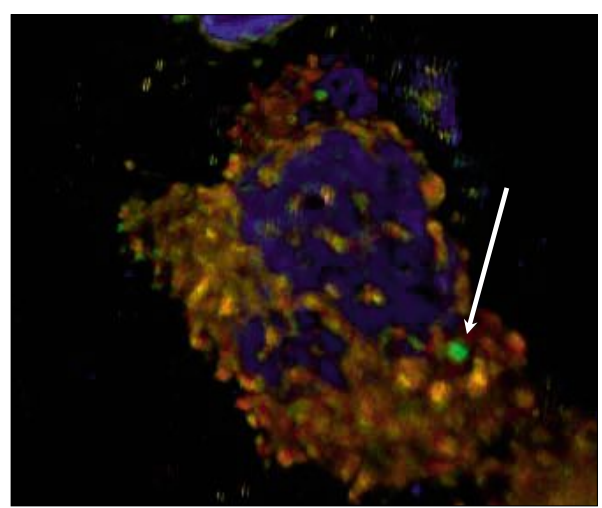

Fig. 5. Confocal image of a HeLa cell where $\mathrm{Pd}(0)$-catalyzed intracellular cross-coupling reaction formed a mitochondria-localized fluorescent dye. The dye is co-localized with Mito Tracker Deep Red (mitochondrial stain) (orange) and the cell nucleolus was stained with Hoechst 33342 (blue). White arrow indicate the presence of $\mathrm{Pd}(0)$-microsphere in the cytosol (green). ${ }^{[33]}$ within living cells. This opens the door for the in situ synthesis of a versatile range of interesting compounds such as activation of prodrugs (Fig. 5). ${ }^{[33]}$

\section{Conclusion}

Microspheres can be reproducibly synthesized, readily functionalized and internalized into a wide range of different cells. They are non-toxic, stable and carry cargos of proteins, RNA and DNA. Applications including sensoring and transition metal catalysis have also been successfully performed inside cells using functionalized microspheres. Synthetic techniques have made it possible to attach multiple cargoes or sensors to the same microsphere allowing several functions on one microsphere within the same cell. The long-term stability of the microsphere enables possibilities ranging from imaging and contrast agents to long-term release of drugs or other biomolecules.

\section{Acknowledgments}

The authors thank The Novartis Foundation, for providing a Novartis Foundation PostDoctoral Research Fellowship to EMVJ.

Received: January 23, 2012

[1] I. Hapala, Crit. Rev. Biotechnol. 1997, 17, 105.

[2] a) F. Madani, S. Lindberg, Ü. Langel, S Futaki, A. Gräslund, J. Biophys. 2011 doi:10.115/2011/414729; b) E. Snyder, S. Dowdy, Pharm. Res. 2004, 21, 389.

[3] a) B.-e. Yingyongnarongkul, M. Howarth T. Elliott, M. Bradley, Chem. Eur. J. 2004, 10, 463; b) A. Unciti-Broceta, L. Moggio, K. Dhaliwal, L. Pidgeon, K. Finlayson, C. Haslett, M. Bradley, J. Mater. Chem. 2010, 21, 2154; c) A. Liberska, A. Lilienkampf, A. Unciti-Broceta, M. Bradley, Chem. Commun. 2011, 47, 12774.

[4] a) C. Dufès, I. F. Uchegbu, A. G. Schätzlein, Adv. Drug Deliv. Rev. 2005, 57, 2177; b) E. M. V. Johansson, J. Dubois, T. Darbre, J.-L. Reymond, Bioorg. Med. Chem. 2010, 18, 6589.

[5] N. W. Shi Kam, T. C. Jessop, P. A. Wender, H Dai, J. Am. Chem. Soc. 2004, 126, 6850.

[6] S. K. Sahoo, S. Parveen, J. J. Panda, Nanomed.: Nanotechnol. Biol. Med. 2007, 3, 20.

[7] H. Zhu, M. J. McShane, J. Am. Chem. Soc. 2005, 127, 13448.

[8] R. M. Sánchez-Martín, M. Muzerelle, N. Chitkul, S. E. How, S. Mittoo, M. Bradley, ChemBioChem 2005, 6, 1341.

[9] a) E. Kaiser, R. L. Colescott, C. D. Bossinger, P. I. Cook, Anal. Biochem. 1970, 34, 995; b) G. L. Ellman, Arch. Biochem. Biophys. 1959, 82, 70; c) J. George Pomonis, R. F. Severson, P. J. Freeman, J. Chromatogr. 1969, 40, 78.

[10] H.-J. Butt, K. Graf, M. Kappl, in 'Physics and Chemistry of Interfaces', Wiley-VCH Verlag $\mathrm{GmbH} \& \mathrm{Co} \mathrm{KGaA}$, Weinheim, 2003.

[11] F. Thielbeer, K. Donaldson, M. Bradley, Bioconj. Chem. 2011, 22, 144.

[12] F. Thielbeer, S. V. Chankeshwara, M. Bradley, Biomacromol. 2011, 12, 825 .

[13] W. R. Algar, D. E. Prasuhn, M. H. Stewart, T. L. Jennings, J. B. Blanco-Canosa, P. E. Dawson, I. L. Medintz, Bioconj. Chem. 2011, 22, 825.

[14] N. Gennet, L. M. Alexander, R. M. Sánchez- 
Martín, J. M. Behrendt, A. J. Sutherland, J. M. Brickman, M. Bradley, M. Li, New Biotechnol. 2009, 25, 442 .

[15] A. Tsakiridis, L. M. Alexander, N. Gennet, R. M. Sanchez-Martin, A. Livigni, M. Li, M Bradley, J. M. Brickman, Biomaterials 2009, $30,5853$.

[16] L. M. Alexander, S. Pernagallo, A. Livigni, R. M. Sánchez-Martín, J. M. Brickman, M. Bradley, Mol. BioSyst. 2009, 6, 399.

[17] D. Bray, Methods Biotechnol. 2000, 13, 235.

[18] L. Alexander, PhD Thesis thesis, The University of Edinburgh, Edinburgh, 2009.

[19] a) W. J. Stark, Angew. Chem. Int. Ed. 2011, 50, 1242; b) M. Lundqvist, J. Stigler, G. Elia I. Lynch, T. Cedervall, K. A. Dawson, PNAS 2008, 105, 14265 .

[20] a) D. Walczyk, F. B. Bombelli, M. P. Monopoli, I. Lynch, K. A. Dawson, J. Am. Chem. Soc. 2010, 132, 5761; b) M. P. Monopoli, D.
Walczyk, A. Campbell, G. Elia, I. Lynch, F. Baldelli Bombelli, K. A. Dawson, J. Am. Chem. Soc. 2011, 133, 2525.

[21] D. E. Wagner, S. B. Bhaduri, Tissue Eng., Part B 2012, 18, 1 .

[22] J. G. Borger, J. M. Cardenas-Maestre, R. Zamoyska, R. M. Sánchez-Martín, Bioconj. Chem. 2011, 22, 1904

[23] S. M. Elbashir, J. Harborth, W. Lendeckel, A. Yalcin, K. Weber, T. Tuschl, Nature 2001, 411 494.

[24] L. M. Alexander, R. M. Sanchez-Martin, M. Bradley, Bioconj. Chem. 2009, 20, 422.

[25] R. M. Sanchez-Martin, L. Alexander, M. Muzerelle, J. M. Cardenas-Maestre, A. Tsakiridis, J. M. Brickman, M. Bradley, ChemBioChem 2009, 10, 1453.

[26] a) S. Pepperl-Klindworth, N. Frankenberg, S. Riegler, B. Plachter, Gene Ther. 2002, 10, 278; b) J. J. Cronican, D. B. Thompson, K. T. Beier,
B. R. McNaughton, C. L. Cepko, D. R. Liu, ACS Chem. Biol. 2010, 5, 747.

[27] A. Roos, W. F. Boron, Physiol. Rev. 1981, 61, 296.

[28] N. Klonis, W. H. Sawyer, J. Fluoresc. 1996, 6, 147.

[29] M. Bradley, L. Alexander, K. Duncan, M Chennaoui, A. C. Jones, R. M. Sánchez-Martín, Bioorg. Med. Chem. Lett. 2008, 18, 313.

[30] O. Eerbeek, E. G. Mik, C. J. Zuurbier, M. van 't Loo, C. Donkersloot, C. Ince, J. Appl. Physiol. 2004, 97, 2042

[31] R. M. Sánchez-Martín, M. Cuttle, S. Mittoo, M. Bradley, Angew. Chem. Int. Ed. 2006, 45, 5472.

[32] K. J. Waldron, J. C. Rutherford, D. Ford, N. J. Robinson, Nature 2009, 460, 823.

[33] R. M. Yusop, A. Unciti-Broceta, E. M. V. Johansson, R. M. Sánchez-Martín, M. Bradley, Nat. Chem. 2011, 3, 239. 